\title{
KAJIAN TEKNIS KEMANTAPAN LERENG TAMBANG DENGAN METODE SLOPE MASS RATING DAN PERHITUNGAN FAKTOR KEAMANAN LERENG MENGGUNAKAN SOFTWARE GEOSTUDIO SLOPE/W 2012 DAN ROCSCIENCE SLIDE V.6 DI PIT BARAT PT PRIMA INDOJAYA MANDIRI
}

\author{
MINE SLOPES STABILITY ASSESSMENT USING SLOPE MASS RATING METHOD AND \\ COMPUTE SLOPE SAFETY FACTOR USING SOFTWARE GEOSTUDIO SLOPE/W 2012 AND \\ ROCSCIENCE SLIDE V.6 IN WESTERN PIT PT PRIMA INDOJAYA MANDIRI
}

\author{
$\mathrm{Akmal}^{1)}$, Sepriadi $^{2)}$ \\ ${ }^{1}$ PT Prima Indojaya Mandiri \\ ${ }^{2}$ Program Studi Teknik Pertambangan Batubara Politeknik Akamigas Palembang, 30257, Indonesia \\ Corresponding Author E-mail: akmal.miner07@gmail.com dan sepri@pap.ac.id
}

\begin{abstract}
In designing an open pit must performed an analysis of slopes stability occurs because of the hoarding process and the excavation so as to contribute the safe design. In this final report will be conducted a slope stability assessment in the western pit of PT Prima Indojaya Mandiri located in Lahat regence. Slope stability assessment performed by testing and find out rock mass strength to get slopes maximum safe angle and potential failure that will occur using Slope Mass Rating method and compute the slope safety factor using Geostudio Slope / W 2012 and Rocscience Slide V.6 using Bishop method. From the result of slope stability assessment, obtained maximum angle of slope formation is $55^{\circ}$ up to $66^{\circ}$ and potential failure in the research area are some joint or many wadge and some rock blocks as well as the smallest safety factor value for slopes with saturated groundwater conditions is 0,878 and the smallest safety factor value for slopes with dry groundwater conditions is 3,492.
\end{abstract}

Keyword: Slope, Bishop, Geostudio, Rocscience.

\begin{abstract}
Abstrak : Dalam merancang suatu tambang terbuka dilakukan suatu analisis terhadap kestabilan lereng yang terjadi karena proses penimbunan maupun penggalian sehingga dapat memberikan kontribusi rancangan yang aman. Pada kajian kemantapan lereng di pit barat PT Prima Indojaya mandiri yang terletak di kabupaten Lahat. Kajian kemantapan lereng dilakukan dengan menguji dan mengetahui kekuatan massa batuan untuk mendapat sudut aman lereng maksimum dan potensi kelongsoran yang akan terjadi dengan metode Slope Mass Rating serta menghitung faktor keamanan lereng menggunakan program Geostudio Slope/W 2012 dan Rocscience Slide V.6 dengan metode Bishop. Dari hasil kajian kemantapan lereng, didapat sudut maksimal pembentukan lereng sebesar $55^{\circ}$ sampai $66,6^{\circ}$ dan potensi kelongsoran pada daerah penelitian berupa beberapa kekar atau banyak baji dan beberapa blok batuan serta nilai faktor keamanan terkecil untuk lereng dengan kondisi airtanah jenuh sebesar 0,878 dan nilai faktor keamanan terkecil untuk lereng dengan kondisi airtanah kering sebesar 3,492.
\end{abstract}

Kata kunci : Slope Mass Rating, Faktor keamanan

\section{PENDAHULUAN}

\subsection{Latar Belakang}

Studi tentang kemantapan lereng pada batuan merupakan suatu hal yang menarik, karena sifat-sifat dan perilakunya yang berbeda dengan kestabilan lereng pada tanah. Kestabilan lereng pada batuan lebih ditentukan oleh adanya bidang-bidang lemah yang disebut dengan bidang diskontinuitas, tidak demikian halnya dengan lereng-lereng pada tanah.

Adanya kegiatan penambangan, seperti penggalian pada suatu lereng akan menyebabkan terjadinya perubahan besarnya gaya-gaya pada lereng tersebut yang mengakibatkan terganggunya kestabilan lereng dan pada akhirnya dapat menyebabkan lereng tersebut longsor. Dalam merancang suatu tambang terbuka dilakukan suatu analisis terhadap kestabilan lereng yang terjadi karena proses penimbunan maupun penggalian sehingga dapat memberikan kontribusi rancangan yang aman dan ekonomis.

Stabilitas dari lereng individual biasanya menjadi masalah yang membutuhkan perhatian yang lebih bagi kelangsungan operasi penambangan setiap harinya. Longsornya lereng pada suatu jenjang, dimana terdapat jalan angkut utama atau berdekatan dengan batas properti atau instalasi penting, dapat menyebabkan bermacam gangguan pada program penambangan. 
Walaupun longsoran yang terjadi relatif kecil, dengan tanda-tanda yang tidak terlihat, tetap saja dapat membahayakan jiwa dan merusak peralatan yang ada.

Salah satu cara untuk mengatasi kondisi tersebut adalah dengan melakukan analisa stabilitas lereng. Maksud dari analisis ini adalah menentukan faktor keamanan (safety factor) baik dari lereng tunggal maupun lereng keseluruhan. Faktor keamanan didefinisikan sebagai perbandingan antara gaya yang menahan dengan gaya yang menggerakkan.

\subsection{Rumusan Masalah}

Penelitian ini dilakukan karena adanya permasalahan teknis untuk kemantapan lereng yang ada pada pit penambangan.

\subsection{Batasan Masalah}

Dalam penelitian ini penulis akan membahas tentang stabilitas lereng tambang terbuka di PT Prima Indojaya Mandiri. Dengan pembahasan sebagai berikut :

1. Menguji dan mengetahui kekuatan massa batuan untuk mendapat sudut aman lereng maksimum dengan metode Slope Mass Rating

2. Analisa Stabilitas Lereng tunggal menggunakan Software Geo Slope/ W 2012, Rockscience Slide 6.0 dan Simple Slope.

3. Analisa Stabilitas Lereng keseluruhan menggunakan Software Geo Slope/ W 2012, Rockscience Slide 6.0.

\subsection{Tujuan Penelitian}

Tujuan dari penelitian ini adalah :

1. Mengetahui sudut aman maksimum lereng di PT Prima Indojaya Mandiri.

2. Mengetahui faktor keamanan lereng tunggal menggunakan softwere Geo Slope/W 2012, Rockscience Slide 6.0 dan Simple Slope.

3. Mengetahui faktor keamanan lereng keseluruhan menggunakan softwere Geo Slope/W 2012, Rockscience Slide 6.0.

4. Menganalisa kebutuhan pompa untuk mine dewateringsump agar sesuai rencana penambangan kuarter berikutnya.

\subsection{Manfaat Penelitian}

Manfaat dari penelitian ini adalah dapat melakuka analisis kestabilan lereng menggunakan Software Geo Slopel W 2012, Rocscience Slide 6.0 dan Simple Slope serta mengetahui sudut aman maksimum dari kekuatan massa batuan di PT Prima Indojaya Mandiri.

\section{TEORI DASAR \\ 2.1 Kestabilan Lereng}

Kestabilan dari suatu jenjang individual dikontrol oleh kondisi geologi daerah setempat, bentuk keseluruhan lereng pada daerah tersebut, kondisi air tanah setempat, dan juga oleh teknik penggalian yang digunakan dalam pembuatan lereng. Faktor pengontrol ini jelas sangat berbeda untuk situasi penambangan yang berbeda dan sangat penting untuk memberikan aturan yang umum untuk menentukan seberapa tinggi atau seberapa landai suatu lereng untuk memastikan lereng itu akan stabil.

Apabila kestabilan dari suatu jenjang dalam operasi penambangan meragukan, maka kestabilannya harus dinilai berdasarkan dari struktur geologi, kondisi air tanah dan faktor pengontrol lainnya yang terjadi pada suatu lereng. Kestabilan lereng pada batuan dipengaruhi oleh geometri lereng, struktur batuan, sifat fisik dan mekanik batuan serta gaya-gaya luar yang bekerja pada lereng tersebut.

Suatu cara yang umum untuk menyatakan kestabilan suatu lereng batuan adalah dengan faktor keamanan. Faktor ini merupakan perbandingan antara gaya penahan yang membuat lereng tetap stabil, dengan gaya penggerak yang menyebabkan terjadinya longsor. Secara matematis faktor kestabilan lereng dinyatakan sebagai berikut :

Dimana :

$$
\mathrm{F}=\mathrm{R} / \mathrm{Fp}
$$

$\mathrm{F}$ = faktor kestabilan lereng

$\mathrm{R}$ = gaya penahan, berupa resultan gayagaya yang membua lereng tetap stabil

$\mathrm{Fp}=$ gaya penggerak, berupa resultan gayagaya yang menyebabkan lereng longsor

Pada kondisi kestabilan lereng dapat di lihat sebagai berikut :

$\mathrm{F}>1,0=$ lereng dalam keadaan stabil

$\mathrm{F}=1,0=$ lereng dalam keadaan seimbang (akan longsor) 
F $<1,0=$ lereng dalam keadaan tidak stabil.

\subsection{Faktor-faktor yang Mempengaruhi Kestabilan Lereng}

Umumnya stabil atau tidaknya suatu lereng tergantung dari beberapa faktor, antara lain :

a. Geometri lereng

Kemiringan dan tinggi suatu lereng sangat mempengaruhi kestabilannya. Semakin besar kemiringan dan ketinggian suatu lereng, maka kestabilan semakin berkurang.

b. Struktur batuan

Strukutur batuan yang sangat mempengaruhi kestabilan lereng adalah bidang-bidang sesar, perlapisan dan rekahan. Struktur batuan tersebut merupakan bidangbidang lemah (diskontinuitas) dan sekaligus sebagai tempat merembesnya air, sehingga batuan lebih mudah longsor.

c. Sifat fisik dan mekanik batuan

Sifat fisik batuan yang mempengaruhi kestabilan lereng adalah : bobot isi (density), porositas dan kandungan air. Sedangkan sifat mekanik batuan antara lain kuat tekan, kuat tarik, kuat geser dan juga sudut geser dalam batuan.

\section{Bobot isi batuan}

Semakin besar bobot isi suatu batuan, maka gaya penggerak yang menyebabkan lereng longsor juga semakin besar. Dengan demikian kestabilan lereng semakin berkurang.

2. Porositas batuan

Batuan yang mempunyai porositas besar akan banyak menyerap air. Dengan demikian bobot isinya menjadi lebih besar, sehingga memperkecil kestabilan lereng. Adanya air dalam batuan akan menimbulkan tekanan air pori yang akan memperkecil kuat geser batuan. Batuan yang mempunyai kuat geser kecil akan lebih mudah longsor. Kuat geser batuan dapat dinyatakan sebagai berikut:

$$
\tau=\mathrm{C}+(\sigma-\mu) \tan \theta
$$

dimana :

$$
\begin{aligned}
\tau & =\text { kuat geser batuan }\left(\operatorname{ton} / \mathrm{m}^{2}\right) \\
\mathrm{C} & \left.=\text { kohesi (ton } / \mathrm{m}^{2}\right) \\
\sigma & =\text { tegangan normal }\left(\operatorname{ton} / \mathrm{m}^{2}\right)
\end{aligned}
$$

$\theta=$ sudut geser dalam (angle of internal friction)

3. Kandungan air dalam batuan

Semakin besar kandungan air dalam batuan, maka tekanan air pori menjadi semakin besar juga. Dengan demikian berarti bahwa kuat geser batuannya menjadi semakin kecil, sehingga kestabilannya berkurang.

4. Kuat tekan, kuat tarik dan kuat geser batuan

Kekuatan batuan biasanya dinyatakan dengan kuat tekan (confined and unconfined compressive strength), kuat tarik (tensile strength) dan kuat geser (shear strength). Batuan yang mempunyai kuat tekan, kuat tarik dan kuat geser besar akan lebih stabil (tidak mudah longsor).

5. Sudut geser dalam (angle of internal friction)

Semakin besar sudut geser dalam, maka kuat geser batuan juga akan semakin besar. Dengan demikian batuan (lereng) akan lebih stabil.

d. Gaya dari luar

Gaya-gaya dari luar yang dapat mempengaruhi (mengurangi) kestabilan suatu lereng adalah :

1. Getaran yang diakibatkan oleh gempa, peledakan dan pemakaian alat-alat mekanis yang berat didekat lereng.

2. Pemotongan dasar (toe) lereng

3. Penebangan pohon-pohon pelindung lereng

2.3 Konsep Massa Batuan, Struktur Batuan dan Bidang Diskontinu

2.3.1 Massa Batuan

Massa batuan merupakan volume batuan yang terdiri dari material batuan berupa mineral, tekstur dan komposisi dan juga terdiri dari bidang-bidang diskontinu, menbentuk suatu material dan saling berhubungan dengan semua elemen sebagai suatu kesatuan. Kekuatan massa batuan sangat dipengaruhi oleh frekuensi bidang-bidang diskontinu yang terbentuk. Oleh sebab itu, massa batuan akan mempunyai kekuatan yang lebih kecil bila dibandingkan dengan batuan utuh. Menurut Hoek \& Bray (1981), massa batuan adalah batuan insitu yang dijadikan diskontinu oleh 
sistem struktur seperti joint, sesar dan bidang perlapisan.

\subsubsection{Struktur Batuan}

Struktur batuan adalah gambaran tentang kenampakan atau keadaan batuan, termasuk di dalamnya bentuk atau kedudukannya. Berdasarkan keterjadiannya, struktur batuan dapat dikelompokkan menjadi:

1. Struktur primer merupakan struktur yang terjadi pada saat proses pembentukan batuan. Misalnya : bidang perlapisan silan (cross bedding) pada batuan sedimen atau kekar akibat pendinginan (cooling joint) pada batuan beku.

2. Struktur skunder merupakan struktur yang terjadi kemudian setelah batuan terbentuk akibat adanya proses deformasi atau tektonik. Misalnya : lipatan (fold), patahan (fault) dan kekar (joint). Bidang diskontinu dapat ditemukan pada struktur primer maupun struktur skunder.

\subsubsection{Bidang Diskontinu}

Secara umum bidang diskontinu merupakan bidang yang memisahkan massa batuan menjadi bagian yang terpisah. Menurut Priest (1993), pengertian bidang diskontinu adalah setiap bidang lemah yang terjadi pada bagian yang memiliki kuat tarik paling lemah dalam batuan. Menurut Gabrielsen (1990), keterjadian bidang diskontinu tidak terlepas dari masalah perubahaan stress (tegangan), temperatur, strain (regangan), mineralisasi dan rekristalisasi yang terjadi pada massa batuan dalam waktu yang panjang.

Beberapa jenis bidang diskontinu yang digolongkan berdasarkan ukuran dan komposisinya adalah:

1. Fault (patahan)

2. Joint (kekar)

3. Bedding (bidang pelapisan)

4. Fracture dan crack

5. Fissure

\subsection{Metode Kesetimbangan Batas}

Metode kesetimbangan batas adalah metode yang digunakan dalam analisis kestabilan lereng untuk longsoran tipe gelinciran. Analisis kestabilan lereng dengan metode ini hanya digunakan kesetimbangan statik saja serta mengabaikan adanya hubungan regangan tegangan yang ada dalam lereng. Asumsi lainnya yaitu geometri dari bentuk bidang longsor harus diketahui dan ditentukan terlebih dahulu (Azizidan Handayani, 2011).

Menurut Bowles (1989) nilai dari faktor keamanan berdasarkan intensitas kelongsorannya dibagi menjadi tiga kelompok, yaitu Nilai Faktor Keamanan suatu lereng kurang dari 1,07 menandakan nilai faktor penggerak lebih besar dari faktor penahan sehingga lereng dalam kondisi rawan longsor. Lereng dengan nilai Faktor Keamanan lebih dari 1,25 yang berarti gaya penahan lebih besar dari gaya penggerak maka lereng dalam kondisi stabil. Tetapi bila nilai kestabilan lerengnya $1,07<\mathrm{FK}<1,25$ lereng dinyatakan dalam kondisi kritis. Kondisi ini menurut Bowles (1984) tidak dikehendaki karena bila ada penambahan gaya penggerak ataupun pengurangan gaya penahan sekecil apapun dapat menyebabkan longsoran.

\subsection{Klasifikasi Massa Batuan}

Klasifikasi massa batuan sangat berguna pada tahap studi kelayakan dan desain awal suatu proyek tambang, di mana sangat sedikit informasi yang tersedia tentang massa batuan dan tegangan serta karakteristik hidrogeologi massa batuan tersebut. Namun, klasifikasi massa batuan tidak dimaksudkan untuk menggantikan pekerjaan desain rinci, sebab untuk desain rinci diperlukan informasi yang lebih lengkap lagi tentang tegangan insitu, sifat massa batuan dan arah penggalian yang biasanya belum tersedia pada tahap awal proyek (Hoek, dkk, 1995). Jika semua informasi ini telah tersedia, maka klasifikasi massa batuan dapat diubah dan disesuaikan dengan kondisi spesifik lapangan. Adapun beberapa tujuan dari klasifikasi massa batuan yaitu (Rai, 1995):

1. Mengidentifikasi parameter terpenting yang mempengaruhi perilaku massa batuan.

2. Membagi formasi massa batuan yang khusus ke dalam grup yangmempunyai perilaku yang sama, yaitu 
kelas massa batuan dengan berbagai kualitas.

3. Memberikan dasar untuk pengertian karakteristik dari tiap kelas massa batuan.

4. Menghubungkan pengalaman dari kondisi massa batuan di satu lokasi dengan pengalaman yang ditemui di lokasi yang lain.

5. Mengambil data kuantitatif dan pedoman untuk rancangan rekayasa (engineering design).

6. Memberikan dasar umum untuk komunikasi diantara para insinyur dan geologiwan.

Agar dapat dipergunakan dengan baik dan cepat maka klasifikasi massa batuan harus mempunyai beberapa sifat seperti berikut (Bieniawski, 1989):

1. Sederhana, mudah diingat dan dimengerti.

2. Sifat-sifat massa batuan yang penting harus disertakan

3. Parameter dapat diukur dengan mudah dan murah

4. Pembobotan dilakukan secara relatif .

5. Menyediakan data-data kuantitatif.

\subsection{Geo Slope Office}

Selain perhitungan manual, stabilitas lereng dapat juga dianalisis menggunakan software komputer. Ada beberapa macam software yang telah dikembangkan. Tapi untuk penelitian ini akan menggunakan software Geo slope Office. Geo Slope/ W 2012 merupakan produk software yang menggunakan batas keseimbangan untuk menghitung faktor keamanan tanah dan lereng. Menganalisa stabilitas lereng, menggunakan batas keseimbangan, serta mempunyai kemampuan untuk menganalisis contoh tanah yang berbeda jenis dan tipe, longsor dan kondisi tekanan air pori dalam tanah yang berubah menggunakan bagian besar contoh tanah. Slopel $W$ merupakan sub program dari Geo Slope yang dapat diintegrasikan dengan sub program lainnya, baik Vadose/ W, Seep/ W, Quake/ W dan Sigma/ W.

\section{METODOLOGI PENELITIAN}

\subsection{Jenis Penelitian}

Jenis penelitian yang dilakukan pada adalah penelitian kuantitatif dengan proses penelitiannya langsung melakukan observasi ke lapangan.

\subsection{Waktu dan Tempat Penelitian}

Penelitian yang dilakukan Penulis tentang Kajian Teknis Kemantapan Lereng Tambang Terbuka di PT Prima Indojaya Mandiri. Penelitian ini dilakukan pada tanggal 12 Februari 2018 sampai dengan 12 April 2018.

\subsection{Metode Penelitian}

Masalah-masalah yang dibahas pada penelitian ini, dapat menggunakan beberapa metode penyelesaiannya sebagai berikut :

1. Studi literatur

Studi literatur dilakukan dengan mencari informasi serta teori yang berhubungan dengan kondisi jalan angkut berdasarkan referensi dari handbook, dan dari sumber referensi lainnya.

2. Observasi

Observasi lapangan ini dilakukan untuk mengamati kondisi nyata struktur geologi yang ada di lapangan dan mencari data secara langsung untuk memperoleh data-data yang diperlukan seperti :

a. Spasi diskontinuitas,

b. Kondisi diskontinuitas,

c. Rock Quality Designation,

d. Rock Mass Rating, dan

e. Slope Mass Rating.

3. Pengumpulan data

Data yang diperlukan dalam penelitian ini mencakup data primer dan data sekunder. Pengumpulan data primer dilakukan dengan cara survey langsung di lapangan, pengambilan data di lapangan. Sedangkan untuk data sekunder meliputi data curah hujan, keadaan geologi daerah penelitian dan peta lokasi penelitian.

4. Pengolahan data

Data diolah berdasarkan dari data primer dan data sekunder, kemudian dimasukkan dalam sebuah tabel (tabulasi) dan data diolah dengan bidang ilmu di segi kemantapan lereng dan berdasarkan tinjauan umum dari hal tentang kemantapan lereng tambang. 


\section{HASIL DAN PEMBAHASAN}

\subsection{Tambang Pit Barat}

Area penambangan di Pit Barat merupakan salah satu area penambangan yang ada di area KP PT Bara Alam Utama yang di kerjakan oleh kontraktor PT Prime Indojaya Mandiri. Berdasarkan peta geologi regional daerah penelitian termasuk kedalam Formasi Muara Enim. Dalam formasi ini terdapat litologi berupa batu pasir, batu lempung, batu lanau, tuff dan batubara.

Pengamatan secara langsung ke lapangan pada tiga lereng single slope dengan material penyusun masing-masing batu lempung, batu lempung kepasiran, dan batu pasir yang memiliki sudut $38^{\circ}$ hingga $49^{\circ}$.

Dari hasil pengamatan, pada masingmasing lereng dengan matreial penyusun claystone, sandy claystone, dan sandstone terdapat beberapa bekas aliran air dan juga memiliki banyak bidang diskontinuitas yang di pengaruhi oleh struktur geologi yang berupa kekar-kekar (gambar 4.2). Pada lereng yang bermaterial claystone terdpat 23 kekar, pada lereng yang bermaterial sandy claystone terdapat 28 kekar, dan pada lereng bermaterial sandstone terdapat 8 kekar dengan masingmasing jarak 50 meter yang dapat diamati dengan keadaan struktur geologi yang bervariasi

\subsection{Rock Mass Rating}

\subsubsection{Kuat Tekan Unaksial}

Nilai Uniaxial Compressive Strength yang didapat dari hasil nilai uji point load dengan menggunakan rumus berikut :

$$
\sigma \mathrm{c}=23 \times \mathrm{Is}_{50}
$$

Tabel 4.1 Nilai Uji Point Load (PL) dan Uji Kuat Tekan Uniaxial Compressive Strength (UCS) Material

\begin{tabular}{|c|c|c|}
\hline Material & PI50 (MPA) & UCS (MPA) \\
\hline Claystone & 0,076 & 1,752 \\
\hline $\begin{array}{c}\text { Sandy } \\
\text { Claystone }\end{array}$ & 0,151 & 3,478 \\
\hline Sandstone & 0,323 & 7,440 \\
\hline
\end{tabular}

\subsubsection{Rock Quality Designation (RQD)}

Priest and Hudson (1976) memberikan persamaan yang menghubungkan frekuensi diskontinuitas $(\lambda)$ dengan RQD sebagai berikut :

$$
\mathrm{RQD}=100 \mathrm{e}^{-0,1 \lambda}(0,1 \lambda+1)
$$

RQD secara rinci diuraikan pada Lampiran C. Dari hasil perhitungan massa batuan memiliki persentase RQD sebagai berikut :

Tabel 4.2 Nilai Persentase Rock Quality Designation

\begin{tabular}{|c|c|}
\hline Material & $\begin{array}{c}\text { Rock Quality } \\
\text { Designation }\end{array}$ \\
\hline Claystone & $84,63 \%$ \\
\hline Sandy Claystone & $81,60 \%$ \\
\hline Sandstone & $94,38 \%$ \\
\hline
\end{tabular}

\subsubsection{Spasi Diskontinuitas}

Bieniawski (1989) tidak menjelaskan bagaimana cara menghitung spasi diskontinuitas apabila terdapat lebih dari satu set diskontinuitas pada suatu massa batuan. Namun, mengacu kepada Edelbro (2003 op.cit. Palmstrom, 2005) yang mengatakan bahwa apabila terdapat lebih dari satu set diskontinuitas dalam massa batuan, maka spasi diskontinuitas yang digunakan adalah spasi diskontinuitas yang memiliki nilai rata-rata terkecil. Berdasarkan hasil penelitian yang didapat, maka dapat diberikan spasi diskontinuitas yang digunakan untuk perhitungan RMR (lihat lampiran C).

Tabel 4.3 Spasi Diskontinuitas Material

\begin{tabular}{|c|c|}
\hline Material & Spasi Diskontinuitas (m) \\
\hline Claystone & 0,2336 \\
\hline Sandy Claystone & 0,1962 \\
\hline Sandstone & 0,3491 \\
\hline
\end{tabular}

\subsubsection{Kondisi diskontinuitas}

Ada lima karakteristik kekar yang maasuk dalam pengertian kondisi kekaryang meliputi kemenerusan (persistence), jarak antar permukaan kekar atau celah (separation/aperture), kekerasan kekar (roughness), material pengisi (infilling/gouge), dan tingkat kelapukan (weathering).

Hasil pengamatan visual terhadap masing-masing lereng dapat dilihat pada tabel 4.4: 
Tabel 4.4 Kondisi Diskontinuitas Material Claystone

\begin{tabular}{|c|l|l|c|}
\hline No. & \multicolumn{1}{|c|}{ Parameter } & \multicolumn{1}{|c|}{ Kriteria } & Value \\
\hline 1 & $\begin{array}{l}\text { Panjang kekar } \\
\text { (persistence/continuity) }\end{array}$ & $3-10 \mathrm{~m}$ & 2 \\
\hline 2 & $\begin{array}{l}\text { Jarak antar permukaan } \\
\text { kekar } \\
\text { (separation/aperture) }\end{array}$ & $0,1-1 \mathrm{~mm}$ & 4 \\
\hline 3 & $\begin{array}{l}\text { Kekerasan kekar } \\
\text { (roughness) }\end{array}$ & Agak kasar & 3 \\
\hline 5 & $\begin{array}{l}\text { Material pengisi } \\
\text { (infilling/gouge) }\end{array}$ & $\begin{array}{l}\text { Lunak <5 } \\
\text { mm }\end{array}$ & 2 \\
\hline \multicolumn{2}{|c|}{ Kondiandising Diskontinus } & Lapuk & 14 \\
\hline
\end{tabular}

Tabel 4.5 Kondisi Diskontinuitas Material Sandy Claystone

\begin{tabular}{|c|l|l|c|}
\hline No. & \multicolumn{1}{|c|}{ Parameter } & \multicolumn{1}{|c|}{ Kriteria } & Value \\
\hline 1 & $\begin{array}{l}\text { Panjang kekar } \\
\text { (persistence/continuity) }\end{array}$ & $3-10 \mathrm{~m}$ & 2 \\
\hline 2 & $\begin{array}{l}\text { Jarak antar permukaan } \\
\text { kekar } \\
(\text { separation/aperture) }\end{array}$ & $1-5 \mathrm{~mm}$ & 1 \\
\hline 3 & $\begin{array}{l}\text { Kekerasan kekar } \\
\text { (roughness) }\end{array}$ & $\begin{array}{l}\text { Agak kasar } \\
\text { (infilling/gouge) }\end{array}$ & $\begin{array}{l}\text { Keras } \\
5 \mathrm{~mm}\end{array}$ \\
\hline 5 & $\begin{array}{l}\text { Kelapukan } \\
\text { (weathering) }\end{array}$ & $\begin{array}{l}\text { Sedikit } \\
\text { lapuk }\end{array}$ & 5 \\
\hline \multicolumn{2}{|c|}{ Kondisi Diskontinus } & 15 \\
\hline
\end{tabular}

Tabel 4.6 Kondisi Diskontinuitas Material Sandstone

\begin{tabular}{|c|l|l|c|}
\hline No. & \multicolumn{1}{|c|}{ Parameter } & Kriteria & Value \\
\hline 1 & $\begin{array}{l}\text { Panjang kekar } \\
\text { (persistence } \\
\text { continuity) }\end{array}$ & $1-3 \mathrm{~m}$ & 4 \\
\hline 2 & $\begin{array}{l}\text { Jarak antar permukaan } \\
\text { kekar } \\
\text { (separation/aperture) }\end{array}$ & $1-5 \mathrm{~mm}$ & 1 \\
\hline 3 & $\begin{array}{l}\text { Kekerasan kekar } \\
\text { (roughness) }\end{array}$ & $\begin{array}{l}\text { Agak kasar } \\
\text { (infilling/gouge) }\end{array}$ & 3 \\
\hline 5 & $\begin{array}{l}\text { Kelapukan } \\
\text { (weathering) }\end{array}$ & $\begin{array}{l}\text { Sedikit } \\
\text { lapuk }\end{array}$ & 5 \\
\hline \multicolumn{2}{|c|}{ Kondisi Diskontinus } & 21 \\
\hline
\end{tabular}

\subsubsection{Kondisi Airtanah}

Dari hasil pengamatan, dapat disimpulkan bahwa kondisi umum air tanah lereng pada masing-masing material adalah lembab (damp), karena saat material di sentuh dengan telapak tangan terasa dingin tetapi tidak terdapat rembesan pada masing-masing lereng tersebut.

Tabel 4.7 Hasil Perhitungan Parameterparameter RMR Material Claystone

\begin{tabular}{|c|l|c|c|}
\hline No. & \multicolumn{1}{|c|}{ Parameter } & Nilai & Rating \\
\hline 1 & $\begin{array}{l}\text { Intact Rock UCS } \\
\text { (Mpa) }\end{array}$ & 1,805 & 1 \\
\hline 2 & RQD (\%) & 84,63 & 17 \\
\hline 3 & $\begin{array}{l}\text { Spasi } \\
\text { Diskontinuitas (cm) }\end{array}$ & 0,2336 & 10 \\
\hline 4 & $\begin{array}{l}\text { Kondisi } \\
\text { Diskontinuitas }\end{array}$ & 14 \\
\hline 5 & Kondisi Air Tanah & Lembab & 10 \\
\hline \multicolumn{2}{|c|}{ RMR } & 52 \\
\hline
\end{tabular}

Tabel 4.8 Hasil Perhitungan Parameterparameter RMR Material Sandy Claystone

\begin{tabular}{|c|l|l|c|}
\hline No. & \multicolumn{1}{|c|}{ Parameter } & \multicolumn{1}{c|}{ Nilai } & Rating \\
\hline 1 & $\begin{array}{l}\text { Intact Rock UCS } \\
(\mathrm{Mpa})\end{array}$ & 3,067 & 1 \\
\hline 2 & RQD (\%) & 81,60 & 17 \\
\hline 3 & $\begin{array}{l}\text { Spasi } \\
\text { Diskontinuitas (m) }\end{array}$ & 0,1962 & 8 \\
\hline 4 & $\begin{array}{l}\text { Kondisi } \\
\text { Diskontinuitas }\end{array}$ & 15 \\
\hline 5 & Kondisi Airtanah & Lembab & 10 \\
\hline \multicolumn{2}{|c|}{ RMR } & 51 \\
\hline
\end{tabular}

Tabel 4.9 Hasil Perhitungan Parameterparameter RMR Material Sandstone

\begin{tabular}{|l|l|l|l|}
\hline No. & Parameter & Nilai & Rating \\
\hline 1 & $\begin{array}{l}\text { Intact Rock UCS } \\
(\mathrm{Mpa})\end{array}$ & 6,806 & 2 \\
\hline 2 & RQD (\%) & 87,77 & 20 \\
\hline 3 & $\begin{array}{l}\text { Spasi } \\
\text { Diskontinuitas (cm) }\end{array}$ & 0,3491 & 10 \\
\hline 4 & $\begin{array}{l}\text { Kondisi } \\
\text { Diskontinuitas }\end{array}$ & 21 \\
\hline 5 & Kondisi Air Tanah & Lembab & 10 \\
\hline RMR & 63 \\
\hline
\end{tabular}

\subsection{Slope Mass Rating (SMR)}

Menurut Robertson (1988) bila RMR lebih besar daripada 40, kemantapan lereng dikontrol oleh orientasi dan kekuatan bidang kontak kekar. Sedangkan bila RMR lebih kecil daripada 30 kelongsoran lereng dapat terjadi 
pada sembarang orientasi kekar. Menurut Laubscher (1975, dalam Djakamihadja dan Soebowo, 1996) nilai sudut lereng yang disarankan dapat diketahui dengan nilai RMR yang telah ada.

Tabel 4.10 Hubungan antara RMR dengan SMR

\begin{tabular}{|c|c|}
\hline Nilai RMR & $\begin{array}{c}\text { Sudut lereng yang didasarkan } \\
\text { (pembobotan massa lereng, SMR) }\end{array}$ \\
\hline $81-100$ & $75^{\circ}$ \\
\hline $61-80$ & $65^{\circ}$ \\
\hline $41-60$ & $55^{\circ}$ \\
\hline $21-40$ & $45^{\circ}$ \\
\hline $0-20$ & $35^{\circ}$ \\
\hline
\end{tabular}

Dari data hasil perhitungan nilai RMR masing-masing material (Tabel 4.6 - 4.8), nilai Slope Mass Rating dari masing-masing material tersebut ialah $55^{\circ}$

Dengan menggunakan batasan bahwa RMR lebih besar dari 20 atau tinggi lereng lebih dari 20 meter, Hall (1985, dalam Djakamihadja dan Soebowo, 1996) memberikan persamaan untuk menduga sudut lereng mantap yang akan digali.

Hasil SMR untuk masing masing material dapat di lihat pada tabel 4.11.

Tabel 4.11 Nilai Slope Mass Rating Masingmasing Material

\begin{tabular}{|l|c|c|c|}
\hline \multicolumn{1}{|c|}{ Material } & RMR & SMR & Slope Range \\
\hline Claystone & 52 & $58,8^{\circ}$ & $55^{\circ}-58,8^{\circ}$ \\
\hline Sandy Claystone & 51 & $58,15^{\circ}$ & $55^{\circ}-58,15^{\circ}$ \\
\hline Sandstone & 63 & $65,95^{\circ}$ & $65^{\circ}-65,95^{\circ}$ \\
\hline
\end{tabular}

Namun pada kenyataan di lapangan sudut masing-masing lereng penelitian tidak lebih dari $50^{\circ}$, yaitu berkisar $38^{\circ}-49^{\circ}$. Hal ini menyebabkan perbedaan data antara data sudut aktual lereng dengan data sudut yang disarankan dengan menggunakan parameter struktur geologi yang mempengaruhinya sehingga menyebabkan perbedaan tingkat keamanan lereng antar keduanya.

\subsection{Parameter Sifat Fisik dan Sifat Mekanik Batuan}

Parameter sifat fisik dan mekanik batuan di PT Prima Indojaya Mandiri di dapat dari hasil pemboran geoteknik dari PT Bara Alam Utama. Nilai parameter ini berupa nilai bobot isi tanah/batuan $\left(\gamma_{\mathrm{w}}\right)$ dengan satuan $\mathrm{kN} / \mathrm{m}^{3}$, nilai kohesi (C) dengan satuan $\mathrm{kPa}$ dan nilai sudut geser dalam $(\Phi)$ dengan satuan derajat $\left(^{\circ}\right)$ yang didapatkan baik melalui uji Direct Shear dan Triaxial maupun Rock Shear Box.

Data Parameter sifat fisik dan mekanik ini di perlukan untuk melakukan pengujian simulasi kestabilan lereng menggunakan software Geostudio dan Rockscience demi mendapatkan nilai faktor keamanan yang lebih akurat. Parameter tersebut dapat di lihat pada tabel 4.12.

Tabel 4.12 Parameter Geoteknik Untuk Slope Stability

\begin{tabular}{|c|c|c|c|c|c|}
\hline \multirow{2}{*}{ Rock Layer } & \multicolumn{5}{|c|}{ Slope Stability Parameter } \\
\hline & Description & $\gamma_{\mathrm{w}}$ & $\mathrm{c}$ & $\Phi$ & Symbol \\
\hline \multirow{4}{*}{$\begin{array}{l}\text { Overburden } \\
\text { A1 }\end{array}$} & Claystone & 20,41 & 69,79 & 19,63 & \\
\hline & Sandstone & 22,90 & 109,65 & 32,47 & \\
\hline & $\begin{array}{l}\text { Silt } \\
\text { Claystone }\end{array}$ & 21,64 & 59,74 & 23,31 & \\
\hline & Claystone & 20,23 & 58,62 & 19,48 & \\
\hline Seam A1 & Coal & 12,12 & 200,00 & 30,00 & \\
\hline $\begin{array}{l}\text { Interburden } \\
\text { A1-A2 }\end{array}$ & Claystone & 21,43 & 58,42 & 22,46 & \\
\hline Seam A2 & Coal & 12,12 & 187,11 & 26,78 & \\
\hline $\begin{array}{l}\text { Interburden } \\
\mathrm{A} 2-\mathrm{B}\end{array}$ & Claystone & 19,84 & 64,78 & 21,46 & \\
\hline Seam B & Coal & 12,29 & 182,15 & 25,99 & \\
\hline \multirow{2}{*}{$\begin{array}{l}\text { Interburden } \\
\text { B-C }\end{array}$} & Claystone & 21,64 & 59,74 & 23,31 & \\
\hline & $\begin{array}{l}\text { Sandy } \\
\text { Claystone }\end{array}$ & 20,78 & 86,09 & 13,19 & \\
\hline Seam $\mathrm{C}$ & Coal & 12,12 & 291,97 & 24,10 & \\
\hline \multirow{3}{*}{ Lower C } & Claystone & 21,64 & 59,74 & 23,31 & \\
\hline & $\begin{array}{l}\text { Sandy } \\
\text { Claystone }\end{array}$ & 21,72 & 88,97 & 20,74 & \\
\hline & Claystone & 20,48 & 61,23 & 22,60 & \\
\hline
\end{tabular}

\subsection{Situasi Tambang Pit Barat Februari 2018}

Tambang pit barat pada bulan februari hanya melakukan aktifitas penanganan lumpur oleh PT Tritunggal sampai akhir bulan april. 
Setelah penangan lumpur selesai PT Prima Indojaya Mandiri akan melanjutkan aktivitas penambangan pada Awal Mei 2018. Ada tiga Penampang yang akan diteliti , masing-masing melalui situasi penambangan per februari 2018. Ketiga penampang yaitu penampang AA', B-B', dan C-C'.

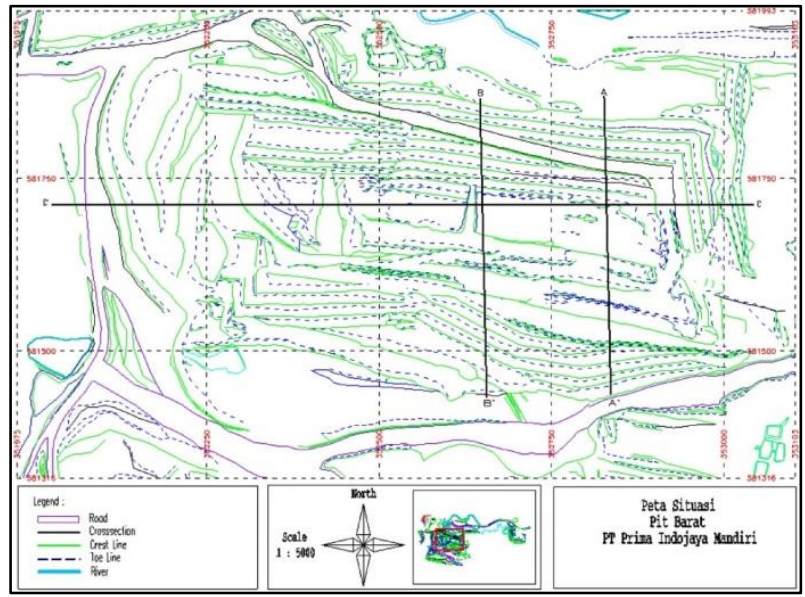

Gambar 4.3 Peta Situasi Penambangan Pit Barat

Dinding lereng pada open pit dibagi menjadi tiga macam yaitu low wall merupakan dinding tambang yang dirancang searah dengan kemiringan kemiringan (dip) lapisan batubara. Bagian low wall dapat dilihat pada titik A' dan B'. High wall adalah dinding tambang yang ditrancang berlawanan arah dengan kemiringan (dip) lapisan batubara. Bagian High wall dapat di lihat pada titik A dan $\mathrm{B}$, sedangkan side wall, yaitu dinding tambang yang dirancang pada sisi samping yang bertujuan sebagai batas dari suatu pit. Bagian side wall dapat dilihat pada titik $\mathrm{C}$ dan $\mathrm{C}^{\prime}$.

Desain lereng area pit barat menggunakan 3 penampang yaitu A-A',B-B', dan C-C'. Penampang A-A' mempunyai tinggi jenjang antara $6,06 \mathrm{~m}$ sampai $21,31 \mathrm{~m}$ dan lebar jenjang $1,75 \mathrm{~m}$ sampai $35,5 \mathrm{~m}$. Desain lereng untuk penampang B-B' yaitu mempunyai tinggi jenjang antara $3,44 \mathrm{~m}$ sampai $13,75 \mathrm{~m}$ dan lebar jenjang $0,69 \mathrm{~m}$ sampai 25,06 m. Desain lereng untuk penampang $\mathrm{C}-\mathrm{C}^{\prime}$ yaitu mempunyai tinggi jenjang antara $5,17 \mathrm{~m}$ sampai $25,70 \mathrm{~m}$ dan lebar jenjang 5,04 m sampai 40,04 m.

\subsection{Analisa Lereng Tunggal Daerah Penelitian}

Pada penelitian ini perhitungan dan desain geometri lereng tunggal (single slope) dilakukan pada daerah penelitian Rock Mass Rating (RMR) yang berada pada lokasi low wall dan lapisan lower $\mathrm{C}$ dengan jenis batuan batu lempung yang memotong garis penampang B-B' dan batu lempung kepasiran yang memotong garis penampang A-A' serta pada lokasi high wall dan lapisan Overburden A1 dengn jenis batuan batu pasir yang memotong garis penampang A-A'. Kajian lereng daerah penelitian RMR masing-masing lapisan dapat dilihat pada tabel 4.13samapai tabel 4.15 di asumsikan memiliki tingkat tinggi muka air tanah jenuh agar mendapat nilai faktor keamanan dengan kondisi lereng kritis.

Tabel 4.13 Kajian lereng daerah penelitin RMR dengan Geostudio Slope/W

\begin{tabular}{|l|c|c|c|c|}
\hline \multicolumn{1}{|c|}{ Material } & $\begin{array}{c}\text { Length } \\
(\mathrm{m})\end{array}$ & $\begin{array}{c}\text { Width } \\
(\mathrm{m})\end{array}$ & $\begin{array}{c}\text { Slope } \\
\left({ }^{\circ}\right)\end{array}$ & FoS \\
\hline Claystone & 4,7 & 2,2 & 49 & 4,129 \\
\hline $\begin{array}{l}\text { Sandy } \\
\text { Claystone }\end{array}$ & 9,44 & 3,97 & 38 & 3,163 \\
\hline Sandstone & 10,75 & 3,12 & 38 & 3,626 \\
\hline
\end{tabular}

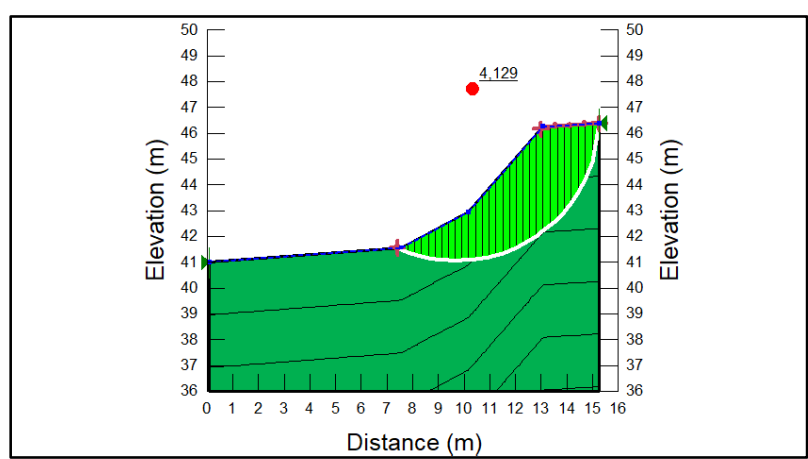

(a)

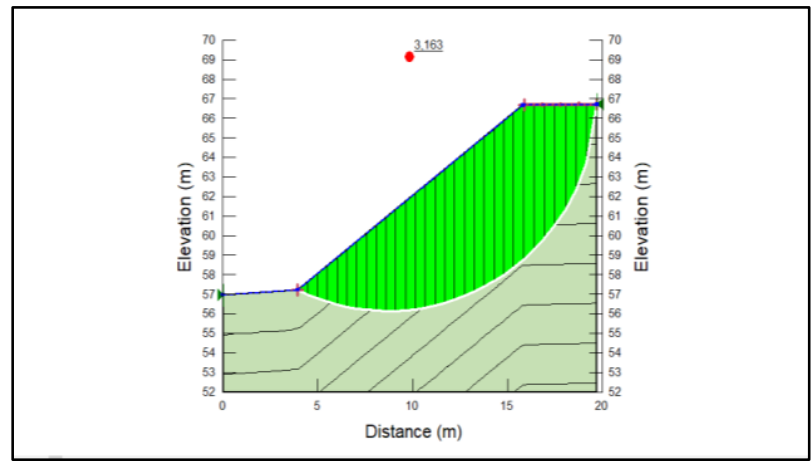

(b) 


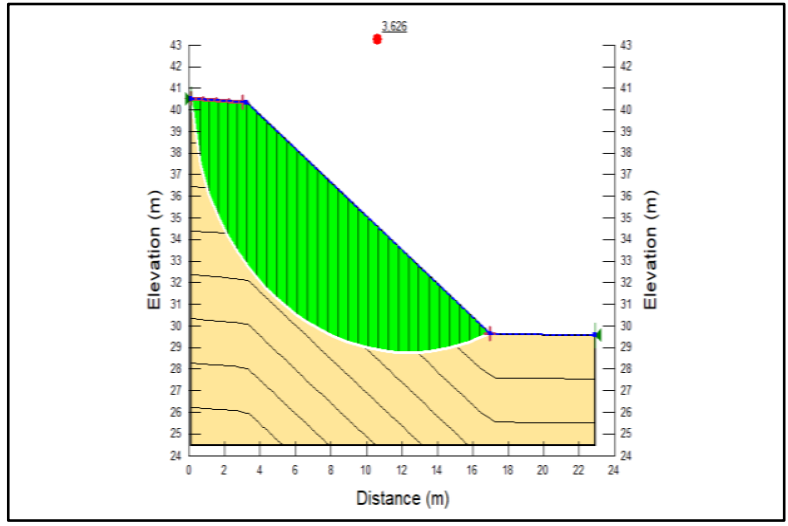

(c)

Gambar 4.4 Hasil Perhitungan Factor of Safety dengan Geostudio Slope/W daerah pengamatan RMR. (a) batulempung, (b) batulempung kepasiran, (c) batupasir

Tabel 4.14 Kajian lereng daerah penelitin RMR dengan Rocscience Slide

\begin{tabular}{|l|l|l|l|l|}
\hline \multicolumn{1}{|c|}{ Material } & $\begin{array}{c}\text { Length } \\
(\mathrm{m})\end{array}$ & \multicolumn{1}{|c|}{$\begin{array}{c}\text { Width } \\
(\mathrm{m})\end{array}$} & $\begin{array}{c}\text { Slope } \\
\left({ }^{\circ}\right)\end{array}$ & \multicolumn{1}{c|}{ FoS } \\
\hline Claystone & 4,7 & 2,2 & 49 & 4,155 \\
\hline $\begin{array}{l}\text { Sandy } \\
\text { Claystone }\end{array}$ & 9,44 & 3,97 & 38 & 3,609 \\
\hline Sandstone & 10,75 & 3,12 & 38 & 3,163 \\
\hline
\end{tabular}

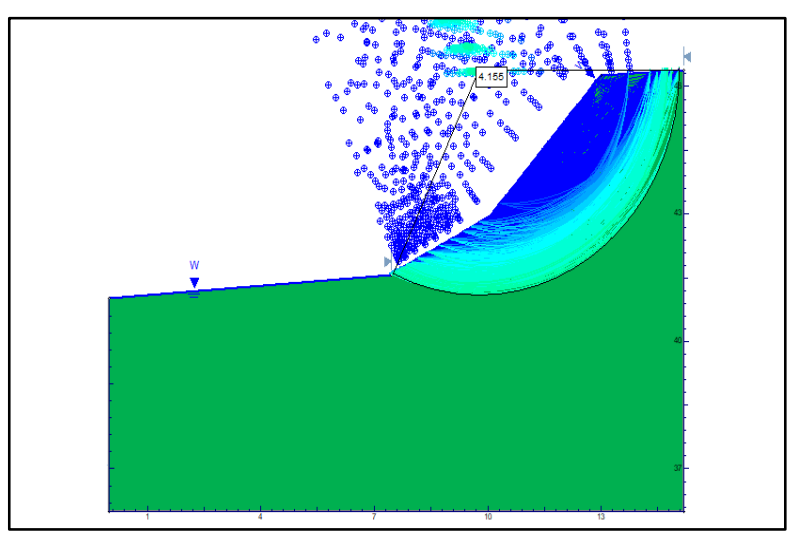

(a)

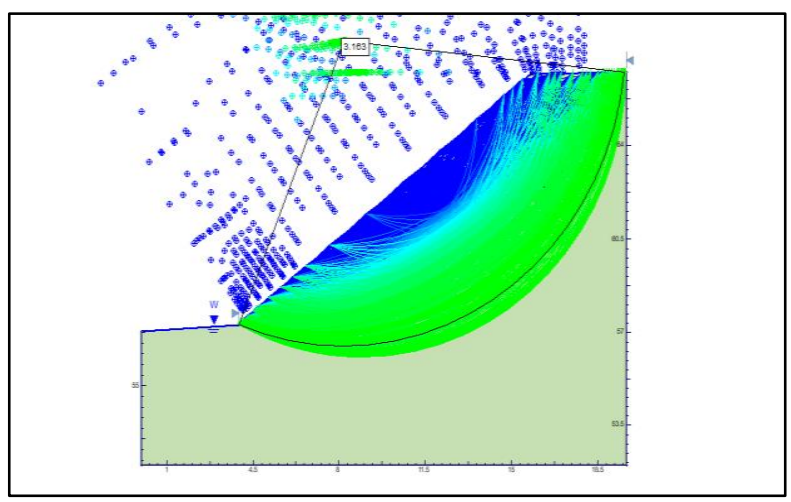

(b)

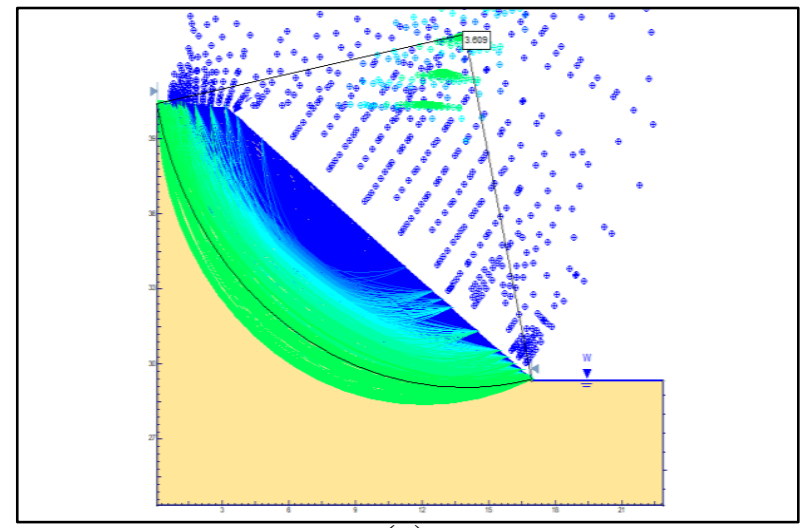

(c)

Gambar 4.5 Hasil Perhitungan Factor of Safety dengan Rocscience Slide Daerah Pengamatan RMR. (a) batu lempung, (b) batulempung kepasiran, (c) batupasir

Tabel 4.15 Kajian Lereng Daerah Penelitin RMR dengan Simple Slope

\begin{tabular}{|l|l|l|l|l|}
\hline \multicolumn{1}{|c|}{ Material } & $\begin{array}{c}\text { Length } \\
(\mathrm{m})\end{array}$ & $\begin{array}{c}\text { Width } \\
(\mathrm{m})\end{array}$ & $\begin{array}{c}\text { Slope } \\
\left({ }^{\circ}\right)\end{array}$ & \multicolumn{1}{c|}{ FoS } \\
\hline Claystone & 4,7 & 2,2 & 49 & 4,09 \\
\hline $\begin{array}{l}\text { Sandy } \\
\text { Claystone }\end{array}$ & 9,44 & 3,97 & 38 & 3,04 \\
\hline Sandstone & 10,75 & 3,12 & 38 & 3,54 \\
\hline
\end{tabular}

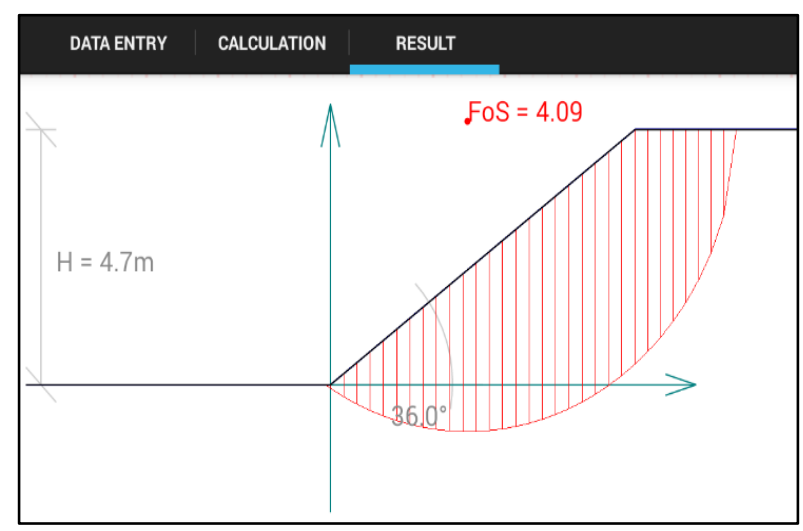

(a)

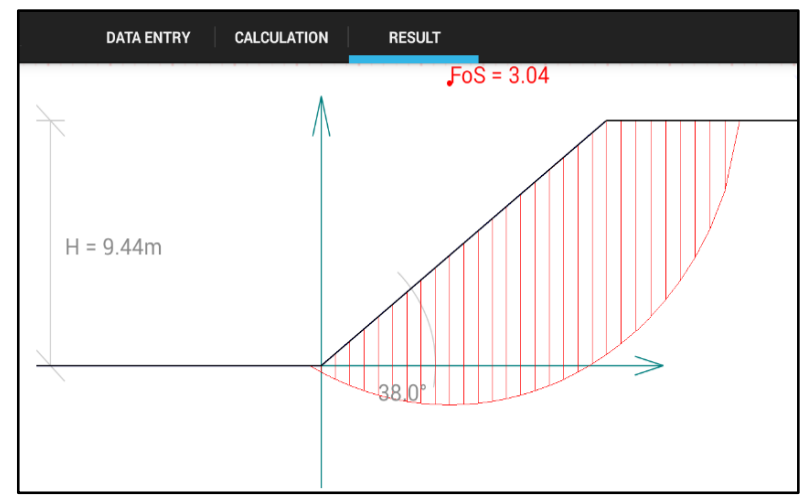

(b) 


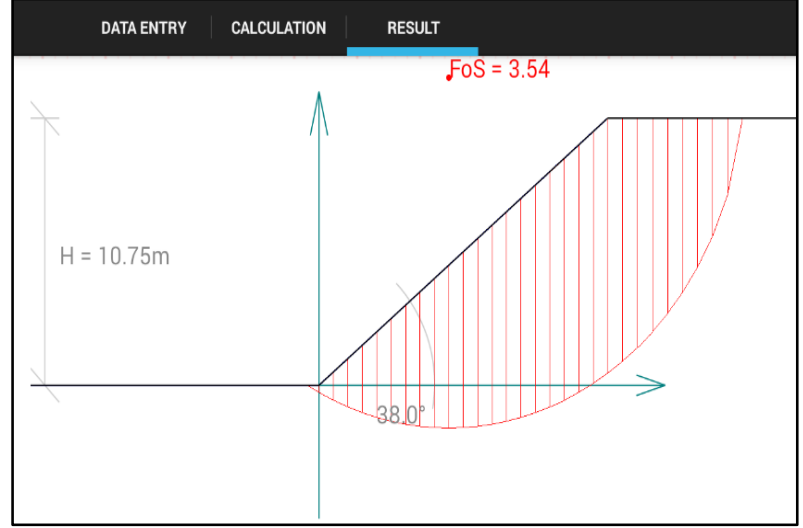

(c)

Gambar 4.6 Hasil Perhitungan Factor of Safety dengan Daerah Pengamatan RMR (a) batulempung, (b) batulempung kepasiran, (c) batupasir

Dari tabel di atas nilai faktor keamanan untuk masing-masing lereng lereng area pengamatan RMR lebih dari nilai faktor keamanan yang di tetapkan perusahaan sebesar 1,5, maka kondisi lereng penelitian dalam kondisi stabil atau tingkat kemungkinan terjadinya longsor kecil.

\subsubsection{Analisa Lereng Tunggal (Single Slope)}

Dalam perhitungan faktor keamanan lereng tungggal (single slope) di lakukan pendekatan-pendekatan sebagai berikut :

1. Masing-masing material mempunyai nilai dinsity, kohesi dan sudut geser dalam.

2. Tinggi muka air tanah dianggap mengikuti tinggi permukaan tanah (jenuh).

3. Perhitungan fakor keamanan menggunakan metode Bishop

4. Faktor keamanan minimal 1,5.

Berdasarkan analisa kestabilan lereng menggunakan Software Gestudio Slope/W, Rockscience Slide V.6 dan Simple Slope maka di dapat nilai faktor keamanan untuk lereng tungggal untuk tiga buah penampang yang dilakukan mulai dari Overburden A1 hingga lapisan lower $C$ dapat di lihat pada lampiran I.

Nilai Faktor Keamanan pada pit barat dapat simpulkan bahwa kondisi lereng tunggal pada penampang $\mathrm{B}$ dan penampang $\mathrm{C}$ tergolong stabil karena lebih dari faktor keamanan ditetapkan perusahaan sebesar 1,5 kecuali, satu lereng tunggal dari penampang A yang memiliki nilai FK berdasarkan Software
Gestudio Slope/W 1,07, Rockscience Slide V.6 1,06 dan Simple Slope 0,86 dengan tinggi lereng $21,31 \mathrm{~m}$ dan lebar $35,50 \mathrm{~m}$ serta sudut $58^{\circ}$ yang berarti lereng tersebut dalam kondisi tidak stabil sehingga kemungkinan terjadinya longsor lebih besar

\subsubsection{Analisa Lereng Keseluruhan (Overall Slope)}

Pendekatan analisis yang dilakukan dalam perhitungan kemantapan lereng keseluruhan (overall slope) tidak jauh berbeda dengan lereng tunggal (single slope). Adapun pendekatan analisis tersebut sebagai berikut :

1. Masing-masing material mempunyai nilai density, kohesi dan sudut geser dalam.

2. Tinggi muka airtanah dibuat dalam keadaan jenuh dan kering.

4. Perhitungan fakor keamanan menggunakan metode Bishop

5. Faktor keamanan minimal 1,5.

Dengan menggunakan menggunakan Software Geostudio Slope/W dan Rockscience Slide V.6 hasil analisis overall slope didapat faktor keamanan sebagai berikut :

a. Overall Slope Section A

Pada lereng keseluruhan penampang A-A' dengan tinggi lereng high wall sebesar 72,56 meter dengan titik tertinggi berada pada elevasi $64,75 \mathrm{mdpl}$ dan titik terendah berada pada $-7,81 \mathrm{mdpl}$ dengan sudut $29^{\circ}$ dan tinggi lereng low wall sebesar 64,13 meter dengan titik tertinggi berada pada elevasi $78,44 \mathrm{mdpl}$ dan titik terendah berada pada elevasi 14,31 mdpl dengan sudut $27^{\circ}$. Kondisi geometri lereng tunggal yang ada di sepanjang penampang A-A' memiliki tinggi dan lebar jenjang yang bervariasi.

b. Overall Slope Section B

Pada lereng keseluruhan penampang B-B' dengan tinggi lereng high wall sebesar 67,19 meter dengan titik tertinggi berada pada elevasi 63,63 mdpl dan titik terendah berada pada $-2,63 \mathrm{mdpl}$ dengan sudut $28^{\circ}$ dan tinggi lereng low wall sebesar 75,13 meter dengan titik tertinggi berada pada elevasi $85 \mathrm{mdpl}$ dan titik terendah berada pada elevasi 9,68 mdpl dengan sudut $27^{\circ}$. Kondisi geometri lereng tunggal yang ada 
di sepanjang penampang B-B' memiliki tinggi dan lebar jenjang yang bervariasi.

c. Overall Slope Section C

Pada lereng keseluruhan penampang C-C' dengan tinggi lereng side wall timur sebesar 60,12 meter dengan titik tertinggi berada pada elevasi 68,3 mdpl dan titik terendah berada pada elevasi $6,20 \mathrm{mdpl}$ dengan sudut $27^{\circ}$ dan tinggi lereng side wall barat sebesar 106,98 meter dengan titik tertinggi berada pada elevasi $100,84 \mathrm{mdpl}$ dan titik terendah berada pada elevasi 3,80 mdpl dengan sudut $17^{\circ}$. Kondisi geometri lereng tunggal yang ada di sepanjang penampang C-C' memiliki tinggi dan lebar jenjang yang bervariasi.

Tabel 4.16 Nilai Faktor Keamanan Keseluruhan Lereng dengan Kondisi Airtanah Jenuh

\begin{tabular}{|l|c|c|c|c|}
\hline \multirow{2}{*}{ Penampang } & \multicolumn{4}{|c|}{ Faktor Keamanan } \\
\cline { 2 - 5 } & $\begin{array}{c}\text { Geostudio } \\
\text { Slope/W }\end{array}$ & Keterangan & Rocscience Slide & Keterangan \\
\hline $\begin{array}{l}\text { Penampang } \\
\text { A-A' sisi } \\
\text { Highwall }\end{array}$ & 0,991 & $\begin{array}{c}\text { Tidak } \\
\text { Stabil }\end{array}$ & 1,003 & Tidak Stabil \\
\hline $\begin{array}{l}\text { Penampang } \\
\text { A-A' sisi } \\
\text { Lowwall }\end{array}$ & 1,193 & $\begin{array}{l}\text { Tidak } \\
\text { Stabil }\end{array}$ & 1,206 & Tidak Stabil \\
\hline $\begin{array}{l}\text { Penampang } \\
\text { B-B' sisi } \\
\text { Highwall }\end{array}$ & 1,070 & $\begin{array}{l}\text { Tidak } \\
\text { Stabil }\end{array}$ & 1,120 & Tidak Stabil \\
\hline $\begin{array}{l}\text { Penampang } \\
\text { B-B' sisi } \\
\text { Lowwall }\end{array}$ & 0,881 & $\begin{array}{l}\text { Tidak } \\
\text { Stabil }\end{array}$ & 0,878 & Tidak Stabil \\
\hline $\begin{array}{l}\text { Penampang } \\
\text { C-C' sisi } \\
\text { Sidewall } \\
\text { Timur }\end{array}$ & 2,149 & Stabil & 2,158 & Stabil \\
\hline $\begin{array}{l}\text { Penampang } \\
\text { C-C' sisi } \\
\text { Sidewall } \\
\text { Barat }\end{array}$ & 1,457 & $\begin{array}{l}\text { Tidak } \\
\text { Stabil }\end{array}$ & 1,460 & Tidak Stabil \\
\hline
\end{tabular}

Tabel 4.17 Nilai Faktor Keamanan Keseluruhan Lereng dengan Kondisi Airtanah Kering

\begin{tabular}{|l|c|c|c|c|}
\hline \multirow{2}{*}{ Penampang } & \multicolumn{4}{|c|}{ Faktor Keamanan } \\
\cline { 2 - 5 } & $\begin{array}{c}\text { Geostudio } \\
\text { Slope/W }\end{array}$ & Keterangan & Rocscience Slide & Keterangan \\
\hline $\begin{array}{l}\text { Penampang } \\
\text { A-A' sisi } \\
\text { Highwall }\end{array}$ & 1,594 & Stabil & 1,608 & Stabil \\
\hline $\begin{array}{l}\text { Penampang } \\
\text { A-A' sisi } \\
\text { Lowwall }\end{array}$ & 1,851 & Stabil & 1,900 & Stabil \\
\hline $\begin{array}{l}\text { Penampang } \\
\text { B-B' sisi } \\
\text { Highwall }\end{array}$ & 1,708 & Stabil & 1,876 & Stabil \\
\hline
\end{tabular}

\begin{tabular}{|l|c|c|c|c|}
\hline \multirow{2}{*}{ Penampang } & \multicolumn{4}{|c|}{ Faktor Keamanan } \\
\cline { 2 - 5 } & $\begin{array}{c}\text { Geostudio } \\
\text { Slope/W }\end{array}$ & Keterangan & Rocscience Slide & Keterangan \\
\hline $\begin{array}{l}\text { Penampang } \\
\text { B-B' sisi } \\
\text { Lowwall }\end{array}$ & 1,426 & $\begin{array}{c}\text { Tidak } \\
\text { Stabil }\end{array}$ & 1,421 & Tidak Stabil \\
\hline $\begin{array}{l}\text { Penampang } \\
\text { C-C' sisi } \\
\text { Sidewall } \\
\text { Timur }\end{array}$ & 3,447 & Stabil & 3,492 & Stabil \\
\hline $\begin{array}{l}\text { Penampang } \\
\text { C-C' sisi } \\
\text { Sidewall } \\
\text { Barat }\end{array}$ & 2,823 & Stabil & 2,839 & Stabil \\
\hline
\end{tabular}

Pada desain lereng keseluruhan (overall slope) memiliki nilai faktor keamanan dengan kondisi airtanah jenuh mulai dari 0,991 hingga 2,158 dan faktor keamanan dengan kondisi air tanah kering mulai dari 1,421 hingga 3,492. Pada sisi low wall penampang A-A' nilai FK lebih besar di bandingkan sisi high wall dan pada sisi high wall penampang B-B' nilai FK lebih besar di bandingkan sisi low wall serta pada sisi side wall timur pada penampang C-C' di dapat nilai FK lebih besar dari sisi side wall barat, hal ini terjadi karena sisi lereng keseluruhan yeng nilai faktor keamanannya lebih besar juga di gunakan untuk jalan angkut selama proses proses penambangan.

\section{KESIMPULAN DAN SARAN 5.1 Kesimpulan}

Berdasarkan pembahasan sebelumnya, maka dapat diambil kesimpulan sebagai berikut:

1. Pada daerah penelitian yang berada pada area penambangan pit barat didapatkan nilai RMR untuk batulempung sebesar 52, batulempung kepasiran sebesar 51 dan batupasir sebesar 55, serta mempunyai nilai SMR untuk batulempung sebesar $55^{\circ}$ sampai $58,8^{\circ}$, batulempung kepasiran sebesar $55^{\circ}$ sampai $58,15^{\circ}$ dan batupasir sebesar $65^{\circ}$ sampai $65,95^{\circ}$.

2. Nilai faktor keamanan lereng tunggal penampang A-A', B-B' dan C-C' :

a. Nilai faktor keamanan lereng single slope pada bagian high wall penampang A-A', B-B' dan berada pada kondisi aman, yaitu FK lebih dari 1,5.

b. Nilai faktor keamanan lereng single slope pada bagian low wall penampang 
B-B' berada pada kondisi aman yaitu FK lebih dari 1,5 namun terdapat satu lereng di bagian low wall penampang A-A' berada pada kondisi tidak stabil, yaitu FK berdasarkan Software Geostudio Slope/W sebesar 1,07, Rocscience Slide V.6 sebesar 1,06 dan Simple Slope sebesar 0,86 .

c. Nilai faktor keamanan lereng single slope pada bagian side wall timur dan barat penampang $\mathrm{C}^{-} \mathrm{C}^{\prime}$ berada pada kondisi aman, yaitu FK lebih dari 1,5.

3. Nilai faktor keamanan lereng keseluruhan penampang A-A', B-B' dan C-C

a. Nilai faktor keamanan overall slope menggunakan Software Gestudio Slope/W dan Rocscience Slide V.6 dengan kondisi airtanah jenuh di dapatlah nilai FK untuk sisi high wall dan low wall pada penampang A-A' dan B-B' serta sisi side wall barat penampang C-C' berada dalam kondisi tidak stabil yaitu FK kurang dari 1,5 sedangkan pada sisi side wall timur penampang $\mathrm{C}^{-\mathrm{C}^{\prime}}$ berada pada kondisi aman dengan $\mathrm{FK}$ yaitu 2,149 berdasarkan Software Gestudio Slope/W dan 2,158 berdasarkan Software Rocscience Slide V.6.

b. Nilai faktor keamanan overall slope menggunakan Software Gestudio Slope/W dan Rocscience Slide V.6 dengan kondisi airtanah kering di dapatlah nilai FK untuk high wall penampang A-A' dan B-B', low wall A$\mathrm{A}^{\prime}$ serta side wall timur dan barat penampang C-C' berada pada kondisi Stabil dengan FK lebih dari 1,5 namun pada sisi low wall penampang B-B' berada pada kondisi kritis dengan nilai FK, yaitu 1,426 berdasarkan Software Gestudio Slope/W dan 1,421 berdasarkan Software Rocscience Slide V.6.

\section{DAFTAR PUSTAKA}

American Society for Testing and Material.1993. ASTM D 653-67. Standard Definition of Term and Symbol. ASTM. West Chonchocken, PA.
Bieniawski, Z.T. 1989. Engineering Rock Mass Classification. New York: Wiley Interscience Publication.

Deere D.U., dan Deere D.W., 1967. Rock Quality Designation (RQD) Index. Department of the Army. U.S. Corps of Engineers. Washington DC.

Deere. 1988. The Rock Quality Index in Practice. Rock Classification System for Engineering Purposes. ASTM STP 984 Kirkaldie Edition. New York.

Edelbro, C. 2003. Rock Mass Strength. Department of Civil Engineering Division of Rock Mechanics. Lulea University of Technology.

Hoek, E and Bray, J.W. 1981. Rock Slope Engineering. London : Institution of Mining and Metallurgy.

Palmstrom, A. 2001. Measurement And Characterization Of Rock Mass Jointing. Chapter 2 of the book: In-Situ Characterization of Rocks. Övre Smestad vei

Swan, Colby C. and Seo, Y K. 1999. Slope Stability Analysis Using Finite Element Technique. $13^{\text {th }}$ lowa ASCE Geotechnical Conference. Williamsburgh, lowa. 
P-ISSN: 2089-5925 E-ISSN: 2621-9328

Antrant

Jurnal Teknik Patra Akademika

PATA

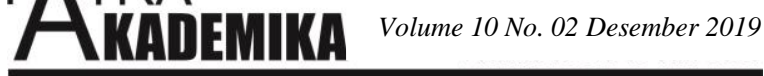

